\title{
Hour Squared Times Microgram per Milliliter
}

National Cancer Institute

\section{Source}

National Cancer Institute. Hour Squared Times Microgram per Milliliter. NCI Thesaurus.

Code C85604.

Hours squared times micrograms per milliliter. 